\title{
FAKTOR YANG MEMENGARUHI STATUS GIZI BALITA DI WILAYAH KERJA PUSKESMAS SIDOMULYO KOTA PEKANBARU
}

\author{
Busyra Hanim \\ PSD III Kebidanan STIKes Payung Negeri Pekanbaru \\ Jl. Tamtama No 6, Labuh Baru. Pekanbaru-Riau-Indonesia \\ Email : hanim.busyra@gmail.com
}

\section{Kata Kunci: \\ Pengetahuan ibu, Masalah makan balita, Pola makan balita, Status gizi balita.}

\begin{abstract}
ABSTRAK
Masa balita merupakan periode emas (golden period) untuk optimalisasi pertumbuhan dan perkembangan otak, namun menjadi masa kritis jika tidak memperoleh asupan gizi sesuai. Kurangnya pengetahuan tentang gizi balita, masalah makan seiring bertambahnya usia balita, serta pola pemberian makan balita yang diterapkan dapat memengaruhi status gizi balita. Hasil Pemantauan Status Gizi (PSG) Riau tahun 2017 berdasarkan Indeks BB/U menunjukkan status gizi buruk 4,3\%, gizi kurang 10,4\%, dan gizi lebih 1,1\%. Berdasarkan data Dinas Kesehatan Kota Pekanbaru tahun 2018 masih ditemukan kasus gizi kurang dan Bawah Garis Merah (BGM) pada balita di wilayah kerja Puskesmas Sidomulyo kota Pekanbaru. Tujuan penelitian untuk mengetahui faktor-faktor yang memengaruhi status gizi balita di wilayah kerja Puskesmas Sidomulyo kota Pekanbaru. Jenis penelitian kuantitatif dengan design korelasi dan pendekatan cross sectional. Populasi penelitian seluruh ibu balita berjumlah 7.341 orang, sampel sebanyak 99 orang yang diambil secara purposive sampling pada posyandu di wilayah kerja Puskesmas Sidomulyo kota Pekanbaru. Instrument penelitian menggunakan kuesioner. Analisis data secara univariate dan bivariate dengan pendekatan uji korelasi Chi-Square (X2). Hasil penelitian didapatkan hubungan yang signifikan antara pengetahuan ibu tentang gizi balita, nilai $\mathrm{p}=0,000(\mathrm{p}<0,05)$, OR (Odds Ratio) 9,360 dan pola makan balita nilai $\mathrm{p}=$ 0,001 ( $\mathrm{p}<0,05$ ), OR (Odds Ratio) 6,838 dengan status gizi balita. Kesimpulan penelitian adalah terdapat hubungan signifikan antara pengetahuan ibu tentang gizi dan pola pemberian makan dengan status gizi balita. Disarankan petugas kesehatan pada Puskesmas Sidomulyo Pekanbaru melakukan pengkajian status gizi balita dengan baik agar dapat memberikan saran dan penatalaksanaan yang tepat untuk memperbaiki status gizi balita.
\end{abstract}

Keywords:

Mother's knowledge,

Toddler's feeding prolems, Toddlers's diet, toddler's nutritional status

Info Artikel

Tanggal dikirim: 27-12-2019

Tanggal direvisi: 28-12-2019

Tanggal diterima: 4-1-2020

DOI: 10.36341 /jomis.v4i1.1118

Attribution-NonCommercial 4.0

International. Some rights

reserved

\section{ABSTRACT}

Toddlerhood is a golden period to optimize growth and brain development, but it becomes a critical period if it does not get the appropriate nutritional intake. Lack of mother's knowledge about toddlers nutrition, feeding problems, and diet can affect the nutritional status of toddlers. The results of Nutrition Status Monitoring (PSG) in Riau at 2017 based on BB/U index, show that poor nutritional status is $4.3 \%$, malnutrition is $10.4 \%$, and $1.1 \%$ over nutrition. Based on data obtained from the Pekanbaru Health Office in 2018 still found cases of malnutrition and Lower Red Line (BGM) in children under five in the working area of Sidomulyo Health Center.The objective of this study was to determine the factors that influence the nutritional status of children under five in the working area of Sidomulyo Health center. The type of research is quantitative with correlation study and cross sectional approach. The study population was all mothers of toddlers totaling 7,341 poeple with 99 poeple sample taken by purposive sampling at Posyandu in the working are of the Sidomulyo Health Center Pekanbaru. The research instrument was questionnaire. Univariate and bivariate data analysis using Chi-Square (X2) correlation test approach. The results showed a significant relationship between maternal knowledge about toddler nutrition $p$ value $=0.000(p<0.05), O R$ (Odds Ratio) 9,360 and toddler's diet $p$ value $=0.001(p<0.05)$, OR (Odds Ratio) 6,838 with nutritional status of toddlers. The conclusion of this study 
that there is a significant relationship between mother's knowledge about toddler nutriton and diet with nutritional status of toddlers. It is recommended that health workers at Sidomulyo Health center conduct a good assessment of toddler's diet, to give appropriate advice and management to improve the nutritional status of toddlers.

\section{PENDAHULUAN}

Berdasarkan data World Health Organitation (WHO) pada tahun 2017 lebih dari setengah kematian balita disebabkan oleh penyakit yang dapat dicegah dan diobati melalui intervensi sederhana dan terjangkau. Anak-anak yang kekurangan gizi, terutama mereka yang kekurangan gizi akut, memiliki risiko kematian yang lebih tinggi. Faktor-faktor yang berhubungan dengan gizi berkontribusi pada sekitar $45 \%$ kematian pada anak di bawah usia 5 tahun [1].

Di Indonesia pada tahun 2015 terdapat 26 kematian balita per 1000 kelahiran hidup, angka ini menjadikan Indonesia berada pada urutan ke-5 tertinggi se-ASEAN [2].

Saat ini Indonesia dihadapkan pada Beban Gizi Ganda atau sering disebut Double Burden, yang artinya pada saat negara ini masih terus bekerja keras mengatasi masalah kekurangan gizi seperti gizi buruk, kurus, dan stunting, namun pada saat yang sama juga harus menghadapi masalah kelebihan gizi atau obesitas khususnya pada balita. [3].

Balita mempunyai risiko untuk mengalami masalah kekurangan gizi, karena pada masa ini sering terjadi masalah makan yang disebabkan balita sudah mulai menjadi konsumen aktif yang cenderung memilih-milih makanan yang akan dikonsumsi [4]. 25-40\% bayi dan balita mengalami masalah makan yang bersifat sementara. Terkadang masalah ini menetap sehingga membutuhkan bantuan tenaga ahli [5].

Menurut Samsudin masalah makan yang berkaitan dengan nutrisi klinis anak adalah segala sesuatu yang berkaitan dengan ketidakmampuan bayi atau anak untuk mengonsumsi sejumlah makanan yang diperlukan secara alamiah dan wajar dengan menggunakan mulutnya secara sukarela[6]. Penelitian di Amerika menemukan empat pola masalah makan pada anak yaitu (1) menolak makan; (2) meminta jenis makanan tertentu; (3) makan hanya sedikit; (4) picky [7]

Hasil pemantauan status gizi tahun 2017 di Pekanbaru menunjukkan status gizi buruk $0,89 \%$, gizi kurang $8,57 \%$, gizi lebih $2 \%$ dan balita yang sangat pendek sebesar 3,83\% dan pendek sebesar 15,39\%. Berdasarkan data Dinas Kesehatan Kota Pekanbaru tahun 2018 dari 21 puskesmas yang ada di kota Pekanbaru didapatkan bahwa Puskesmas Sidomulyo memiliki kasus balita BGM 172 balita dan gizi kurang ditemukan 69 balita.

Gizi kurang merupakan masalah gizi terbesar yang ditemukan di Indonesia. Gizi kurang tidak hanya disebabkan oleh jumlah konsumsi tetapi juga pada pola pemberian makan balita secara keseluruhan yang tidak mencukupi kebutuhan balita. Susunan hidangan yang tidak seimbang atau kurang beragam secara kualitas juga berperan secara tidak langsung, yang dipengaruhi oleh kemampuan ekonomi, budaya, dan pengetahuan orang tua[8].

Berdasarkan uraian latar belakang tersebut maka peneliti tertarik untuk melakukan penelitian tentang "Faktor Yang Memengaruhi Status Gizi Balita Di Wilayah Kerja Puskesmas Sidomulyo Pekanbaru"

\section{TINJAUAN PUSTAKA}

Hasil penelitian [12] tentang faktorfaktor yang berhubungan dengan status gizi anak balita di Desa Teluk Rumbia Kecamatan Singkil Kabupaten Aceh Singkil mendapatkan bahwa pengetahuan ibu memiliki hubungan yang bermakna dengan status gizi balita. 
Hasil penelitian [11] tentang hubungan pengetahuan ibu tentang pola pemberian makan dengan status gizi balita di wilayah kerja puskesmas Gapura Kabupaten Sumenep juga mendapatkan adanya hubungan bermakna antara pengetahuan ibu tentang pola pemberian makan dengan status gizi balita.

Masalah makan kebanyakan terjadi pada masa batita awal. Hal ini berkaitan dengan proses perkembangannya, balita mengalami masa peralihan dari bentuk makanan lunak menjadi makanan biasa. Dia harus belajar mengunyah makanan, bukan lagi menelan, sehingga balita cenderung mengalami malas makan [18].

Penelitian di Amerika menemukan empat pola masalah makan pada anak yaitu menolak makan; meminta jenis makanan tertentu; makan hanya sedikit; picky[7] Umumnya masalah tersebut tidak mengalami pengurangan masukan zat gizi sehingga tumbuh kembang tidak mengalami gangguan. Ada enam situasi makan yang merupakan bagian dari dinamika tumbuh kembang anak yang normal yaitu: food jag (makan hanya satu jenis makanan); food strikers (menolak apa yang disajikan dan minta makanan lain; $t v$ habbit (akan makan bila menonton televisi); the complainers (selalu mengeluh apa yang disajikan; white food diet (hanya makan yang bewarna putih seperti roti, kentang, makaroni, atau nasi saja); dan takut mencoba makanan baru[20].

Hasil penelitian [15] mendapatkan bahwa ada hubungan signifikan antara pola makan dengan status gizi balita di wilayah kerja Puskesmas Nanggalo Padang. Jumlah asupan kalori yang cukup yang sesuai dengan Angka Kecukupan Gizi (AKG), pemberian makanan yang bervariasi, dan diikuti dengan menerapkan cara pemberian makan yang benar pada anak akan menghasilkan status gizi baik.

\section{METODE}

Jenis penelitian adalah kuantitatif dengan design korelasi dan pendekatan cross sectional. Variabel independen dalam penelitian ini adalah status gizi balita. Variabel dependen meliputi: pengetahuan ibu tentang gizi balita, masalah makan balita, dan pola pemberian makan balita. Populasi penelitian ini adalah seluruh ibu yang memiliki balita berjumlah 7.341 orang dan dijadikan sampel sebanyak 99 orang dengan menggunakan teknik purposive sampling dari ibu yang membawa balitanya ke posyandu di wilayah kerja Puskesmas Sidomulyo kota Pekanbaru. Untuk mendapatkan data pengetahuan ibu tentang gizi balita dan masalah makan balita menggunakan instrumen penelitian berupa lembar kuesioner. Data staus gizi balita dilihat dari hasil penimbangan balita di posyandu yang sudah tercantum pada buku KIA. Analisis data dilakukan secara univariate untuk menggambarkan masingmasing variabel dan teknik analisis data bivariate dengan pendekatan uji korelasi Chi-Square (X2).

\section{HASIL DAN PEMBAHASAN}

Berdasarkan analisis data secara univariat dari setiap variabel penelitian yang terdiri dari karakteristik responden, pengetauan tentang gizi balita, masalah makan balita, pola pemberian makan balita, dan status gizibalita. 


\section{1) Analisis Univariate}

Tabel. 1

Distribusi Frekuensi Karakteristik Responden di Puskesmas Sidomulyo Kota Pekanbaru Tahun 2019

\begin{tabular}{lcc}
\hline \multicolumn{1}{c}{ Kategori } & Frekuensi & \% \\
\hline Usia & & \\
Usia Reproduksi (20-35) & 82 & 82,8 \\
Diluar Usia Reproduksi & 17 & 17,2 \\
\hline Pendidikan & 16 & 16,2 \\
Pendidikan Dasar & 72 & 72,7 \\
Pendidikan Menengah & 11 & 11,1 \\
Pendidikan Tinggi & & \\
\hline Paritas & 34 & 34,3 \\
Anak pertama & 65 & 65,7 \\
>Anak pertama & & \\
\hline Usia Balita & 21 & 21,2 \\
12-24 bulan & 32 & 32,3 \\
25-36 bulan & 46 & 46,5 \\
37-60 bulan & $\mathbf{9 9}$ & $\mathbf{1 0 0}$ \\
\hline
\end{tabular}

Berdasarkan Tabel 1 diketahui bahwa usia ibu balita mayoritas pada usia reproduksi (20-35 tahun) yaitu 82,8\%, tingkat pendidikan menengah sebanyak
72 responden $(72,7 \%)$, memiliki anak $>1$ orang sebanyak 65 orang $(65,7 \%)$, dan sebagian besar usia balita antara 37-60 bulan sebanyak 46 orang $(46,5 \%)$.

Tabel 2

Distribusi Frekuensi Responden Berdasarkan Pengetahuan Tentang Gizi Balita di Puskesmas Sidomulyo Kota Pekanbaru Tahun 2019

\begin{tabular}{|c|c|c|}
\hline \multirow{2}{*}{\multicolumn{3}{|c|}{$\begin{array}{l}\text { Kategori } \\
\text { Pengetahuan }\end{array}$}} \\
\hline & & \\
\hline Rendah & 55 & 55,6 \\
\hline Tinggi & 44 & 44,4 \\
\hline Jumlah & 99 & 100 \\
\hline
\end{tabular}

Berdasarkan tabel 2 dapat diketahui bahwa mayoritas responden di wilayah kerja Puskesmas Sidomulyo Pekanbaru tahun 2019 memiliki pengetahuan rendah tentang gizi balita yaitu sebanyak 55 orang $(55,6 \%)$.

Tabel 3

Distribusi Frekuensi Responden Berdasarkan Masalah Makan Balita di Puskesmas Sidomulyo Kota Pekanbaru Tahun 2019

\begin{tabular}{|c|c|c|}
\hline Kategori & Frekuensi & $\%$ \\
\hline \multicolumn{3}{|l|}{ Masalah makan balita } \\
\hline Ada & 67 & 67,7 \\
\hline Tidak ada & 32 & 32,3 \\
\hline Jumlah & 99 & 100 \\
\hline
\end{tabular}

Dari tabel 3 diketahui bahwa mayoritas responden di wilayah kerja Puskesmas
Sidomulyo tahun 2019 memiliki masalah makan balita sebanyak 67 orang $(67,7 \%)$. 
Tabel 4

Distribusi Frekuensi Responden Berdasarkan Pola Pemberian Makan Balita di Puskesmas Sidomulyo Kota Pekanbaru Tahun 2019

\begin{tabular}{|c|c|c|}
\hline \multirow{2}{*}{\multicolumn{3}{|c|}{$\begin{array}{l}\text { Kategori } \\
\text { Pola pemberian makan balita }\end{array}$}} \\
\hline & & \\
\hline Kurang & 71 & 71,7 \\
\hline Baik & 28 & 28,3 \\
\hline Jumlah & 99 & 100 \\
\hline
\end{tabular}

Berdasarkan tabel 4 diketahui bahwa mayoritas responden di wilayah kerja Puskesmas Sidomulyo Pekanbaru tahun
2019 memiliki pola pemberian makan balita kurang baik sebanyak 71 orang $(71,7 \%)$.

Tabel 5

Distribusi Frekuensi Responden Berdasarkan Status Gizi Balita di Puskesmas Sidomulyo Kota Pekanbaru Tahun 2019

\begin{tabular}{lccc}
\hline & Kategori & Frekuensi & \% \\
\hline Status Gizi Balita & & 35 & 35,4 \\
Kurang & & 64 & 64,6 \\
Baik & Jumlah & $\mathbf{9 9}$ & $\mathbf{1 0 0}$ \\
\hline
\end{tabular}

Dari tabel 5 diketahui bahwa mayoritas responden di wilayah kerja Puskesmas Sidomulyo Pekanbaru tahun 2019 memiliki balita dengan status gizi baik sebanyak 64 orang $(64,4 \%)$.

\section{2) Analisis Bivariate}

\section{Tabel 6}

Faktor yang Memengaruhi Status Gizi Balita di Wilayah Kerja Puskesmas Sidomulyo kota Pekanbaru tahun 2019

\begin{tabular}{|c|c|c|c|c|c|c|}
\hline \multirow{2}{*}{ No } & \multirow{2}{*}{$\begin{array}{c}\text { Faktor } \\
\text { yang memengaruhi }\end{array}$} & \multicolumn{2}{|c|}{ Status Gizi } & \multirow{2}{*}{ Total } & \multirow[b]{2}{*}{$p$} & \multirow{2}{*}{ OR } \\
\hline & & Kurang & Baik & & & \\
\hline \multirow[t]{3}{*}{1} & Pengetahuan ibu tentang gizi balita & & & & \multirow{3}{*}{0.000} & \multirow{3}{*}{9.360} \\
\hline & - Rendah & $\begin{array}{c}30 \\
(54.5 \%)\end{array}$ & $\begin{array}{c}25 \\
(45.2 \%)\end{array}$ & $\begin{array}{c}55 \\
(100 \%)\end{array}$ & & \\
\hline & Tinggi & $\begin{array}{c}5 \\
(11.3 \%)\end{array}$ & $\begin{array}{c}39 \\
(88.6 \%)\end{array}$ & $\begin{array}{c}44 \\
(100 \%)\end{array}$ & & \\
\hline \multirow[t]{3}{*}{2} & Masalah makan balita & & & & & \\
\hline & - Ada & $\begin{array}{c}28 \\
(41.7 \%)\end{array}$ & $\begin{array}{c}39 \\
(58.2 \%)\end{array}$ & $\begin{array}{c}67 \\
(100 \%)\end{array}$ & \multirow{2}{*}{0.53} & \multirow{2}{*}{2.564} \\
\hline & - Tidak ada & $\begin{array}{c}7 \\
(21.8 \%)\end{array}$ & $\begin{array}{c}25 \\
(78.1 \%)\end{array}$ & $\begin{array}{c}32 \\
(100 \%)\end{array}$ & & \\
\hline \multirow[t]{3}{*}{3} & Pola pemberian makan balita & & & & \multirow{3}{*}{0.001} & \multirow{3}{*}{6.838} \\
\hline & - Kurang & $\begin{array}{c}32 \\
(45 \%)\end{array}$ & $\begin{array}{c}39 \\
(54.9 \%)\end{array}$ & $\begin{array}{c}71 \\
(100 \%)\end{array}$ & & \\
\hline & - Baik & $\begin{array}{c}3 \\
(10.7 \%) \\
\end{array}$ & $\begin{array}{c}25 \\
(89.2 \%) \\
\end{array}$ & $\begin{array}{c}28 \\
(100 \%) \\
\end{array}$ & & \\
\hline
\end{tabular}

Berdasarkan tabel 6 dapat diketahui terdapat hubungan yang signifikan antara faktor pengetahuan ibu tentang gizi balita dengan status gizi balita, $P$ value sebesar $0,000 \quad(\mathrm{P}<0,05)$ dan OR (Odds Ratio)
9.360. Hasil ini menunjukkan bahwa ibu yang memiliki pengetahuan tinggi tentang gizi balita memiliki balita dengan status gizi baik sebanyak 9.3 kali dibandingkan ibu dengan pengetahuan rendah. 
Hasil penelitian menunjukkan bahwa faktor pola pemberian makan balita memiliki hubungan signifikan dengan status gizi balita, $P$ value sebesar 0.001 ( $\mathrm{P}<0,05)$ dan OR (Odds Ratio) 6,838. Balita dengan pola makan yang baik memiliki status gizi baik 6,3 kali dibandingkan balita dengan pola makan kurang baik.

Hasil uji statistik menunjukkan hubungan faktor masalah makan balita dengan status gizi balita tidak signifikan Pvalue 0,53 (p>0,05).

\section{Status Gizi Balita}

Berdasarkan Tabel 5 diperoleh data bahwa dari 99 responden 35 responden dengan kategori gizi kurang $(35,4 \%)$ serta sebanyak 64 responden tergolong dalam kriteria gizi baik/gizi lebih $(64,6 \%)$.

Penilaian status gizi dapat dilakukan dengan empat cara yaitu pengukuran antropometri; pemeriksaan klinis; pemeriksaan biokimia; dan pemeriksaan biofisis[9]. Pengukuran antropometri merupakan penilaian status gizi yang paling mudah dilakukan namun sudah dapat memberikan hasil yang cukup signifikan. Pengukuran antropometri menghasilkan tiga macam indeks antropometri, meliputi tinggi atau panjang badan berdasarkan umur (TB/U atau $\mathrm{PB} / \mathrm{U})$; berat badan menurut tinggi atau panjang badan $(\mathrm{BB} / \mathrm{TB}$ atau $\mathrm{BB} / \mathrm{PB})$; serta berat badan menurut umur $(\mathrm{BB} / \mathrm{U})$.

Berat badan menurut umur merefleksikan berat badan relatif dibandingkan umur anak. Indeks BB/U dikategorikan menjad gizi kurang/gizi buruk (<-2SD) dan gizi baik/gizi lebih ( $\geq-2 \mathrm{SD})$, tetapi tidak dapat digunakan untuk mengklasifikasikan apakah seorang anak mengalami kelebihan berat badan atau sangat gemuk (gizi baik atau gizi lebih saja). Sedangkan berat badan yang rendah dapat disebabkan oleh tubuh yang pendek/stunting (kronis), tubuh yang cenderung kurus/thinnes (akut), maupun keduanya[10].

\section{Pengetahuan Ibu Tentang Gizi Balita}

Bertambahnya usia anak, makanan yang diberikan harus lebih beragam serta bergizi seimbang guna menunjang tumbuh kembang dan status gizi balita. Ibu sangat berperan penting untuk menentukan jenis makanan yang akan dikonsumsi oleh anak[10].

Gizi kurang merupakan masalah gizi terbesar yang ditemukan di Indonesia. Gizi kurang tidak hanya disebabkan oleh jumlah konsumsi tetapi juga pada pola pemberian makan balita secara keseluruhan yang kurang/tidak mencukupi kebutuhan. Susunan hidangan yang tidak seimbang atau beragam (kualitas) turut menjadi factor penyumbang tidak langsung yang dapat dipengaruhi dari segi ekonomi, budaya dan pengetahuan orang tua.

Berdasarkan hasil penelitian diketahui bahwa terdapat hubungan yang signifikan antara pengetahuan ibu tentang gizi balita dengan status gizi balita dengan Pvalue sebesar 0,000 ( $<<0,05)$ dan OR (Odds Ratio) 9,360. Hasil ini menunjukkan bahwa ibu yang memiliki pengetahuan tinggi memiliki balita dengan status gizi baik 9,3 kali dibandingkan ibu dengan pengetahuan rendah.

Pada Tabel 6 didapatkan balita dengan status gizi kurang lebih banyak dari ibu berpengetahuan rendah tentang gizi balita lebih banyak ibu berpengetahuan kurang memiliki balita dengan status gizi kurang sebanyak 30 responden $(54,4 \%)$ dibandingkan ibu berpengetahuan tinggi dengan status gizi balita kurang sebanyak 5 responden $(11,3 \%)$.

Didukung dengan hasil penelitian Sari (2018) yang menyatakan bahwa terdapat hubungan signifikan antara pengetahuan pola pemberian makan dengan status gizi balita $(\mathrm{p}<0,05)[11]$. Hasil penelitian Ihsan juga mendapatkan lebih banyak ibu dengan pengetahuan rendah memiliki balita dengan status gizi kurang dibandingkan status gizi baik. Temuan $11,3 \%$ responden dengan pengetahuan tinggi namun gizi balita kurang, kondisi ini bisa disebabkan karena 
kurang menerapkan informasi tentang gizi balita dalam kehidupan sehari-hari. Didukung dengan hasil penelitian Indra menjelaskan salah satu penyebab masalah gizi kurang yaitu kurangnya pengetahuan tentang gizi atau kurang menerapkan informasi tersebut dalam kehidupan seharihari[12].

\section{Pola Pemberian Makan Balita}

Pola makan yang baik terdiri dari konsumsi makanan yang berkualitas yaitu makanan yang sehat dan bervariasi, konsumsi makanan yang cukup dari segi kualitas diikuti dengan menerapkan perilaku makan yang benar. Jika hal ini diterapkan maka akan menghasilkan status gizi anak yang normal[13].

Pola pemberian makan dipengaruhi oleh factor fisologis, psikologis, social dan budaya. Factor tersebut mampu menentukan pilihan terhadap makanan apa saja yang akan dikonsumsi, siapa saja yang akan mengonsumsi, serta kapan makanan tersebut boleh atau tidak boleh untuk dikonsumsi[14].

Berdasarkan hasil penelitian didapatkan pola pemberian makan balita memiliki hubungan yang signifikan dengan status gizi balita, Pvalue 0,001 ( $<<0,05)$ dan OR (Odds Ratio) 6.838. Hasil ini menjelaskan bahwa balita dengan pola makan baik memiliki status gizi baik 6,3 kali dibandingkan dengan balita dengan pola pemberian makan kurang baik.

Pada Tabel 4 dan 6 menunjukkan bahwa mayoritas pola pemberian makan pada balita yang dilakukan orang tua masih tergolong kurang baik $(71,7 \%)$. Pola pemberian makan balita yang kurang baik memiliki balita dengan kategori status gizi kurang pada 32 responden (45\%).

Hasil penelitian ini didukung oleh penelitian Sari (2014) yang mendapatkan bahwa ada hubungan signifikan $(\mathrm{p}=0,00)$ antara pola makan dengan status gizi balita di wilayah kerja Puskesmas Nanggalo Padang. Jumlah asupan kalori yang cukup yang sesuai dengan Angka Kecukupan Gizi (AKG), pemberian makanan yang bervariasi, dan diikuti dengan menerapkan cara pemberian makan yang benar pada anak akan menghasilkan status gizi baik [15]. Diperkuat oleh penelitian Tella (2013) di Mapanget yang mendapatkan bahwa hubungan pola makan dengan status gizi sangat kuat. Asupan gizi seimbang dari makanan berperan penting dalam proses pertumbuhan balita diiringi dengan pola makan yang baik dan teratur perlu diperkenalkan sejak dini, antara lain dengan memperkenalkan jam-jam makan dan variasi makanan untuk membantu mengkoordinasikan kebutuhan pola makan sehat pada balita[16].

Bertambahnya usia anak, makanan yang diberikan harus lebih beragam serta bergizi seimbang guna menunjang tumbuh kembang dan status gizi balita. Ibu sangat berperan penting untuk menentukan jenis makanan yang akan dikonsumsi oleh anak. Pemberian pola makan yang memadai berhubungan dengan baiknya kualitas konsumsi makanan anak yang akhirnya akan meningkatkan kecukupan zat gizi. Tingkat kecukupan gizi yang didapat merupakan salah satu factor yang dapat memengaruhi status gizi balita[17].

\section{Masalah Makan Balita}

Hasil penelitian menunjukkan hubungan masalah makan balita dengan status gizi balita tidak signifikan. Didapatkan $28 \quad(41,7 \%)$ orang balita dengan masalah makan memiliki status gizi kurang, namun sebanyak 39 (58.2\%) orang balita dengan masalah makan memiliki status gizi baik.

Masalah makan kebanyakan terjadi pada masa batita awal. Hal ini berkaitan dengan proses perkembangannya, balita mengalami masa peralihan dari bentuk makanan lunak menjadi makanan biasa. Dia harus belajar mengunyah makanan, bukan lagi menelan, sehingga balita cenderung mengalami malas makan[18].

$45 \%$ anak yang mempunyai masalah makan dengan keluhan utama tidak ada nafsu makan, ternyata memiliki berat dan tinggi badan yang normal. 
Kesibukan orang tua di perkotaan meningkatkan persepsi "susah makan", sehingga susu dijadikan sebagai makanan atau menu utama anak mereka tanpa disertai makanan padat[19].

Penelitian di Amerika menemukan empat pola masalah makan pada anak yaitu menolak makan; meminta jenis makanan tertentu; makan hanya sedikit; picky[7] Umumnya masalah tersebut tidak mengalami pengurangan masukan zat gizi sehingga tumbuh kembang tidak mengalami gangguan. Ada enam situasi makan yang merupakan bagian dari dinamika tumbuh kembang anak yang normal yaitu: food jag (makan hanya satu jenis makanan); food strikers (menolak apa yang disajikan dan minta makanan lain; $t v$ habbit (akan makan bila menonton televisi); the complainers (selalu mengeluh apa yang disajikan; white food diet (hanya makan yang bewarna putih seperti roti, kentang, makaroni, atau nasi saja); dan takut mencoba makanan baru[20]

Sudjatmoko menjelaskan bahwa masalah makan merupakan hal yang umum dikeluhkan orang tua atau pengasuh. Perilaku picky merupakan proses dalam tumbuh kembang anak yang hanya bersifat sementara, karena anak tidak akan membiarkan dirinya kelaparan seperti yang dikuatirkan orang tua. Anamnesa yang baik sangat bermanfaat dalam menghadapi masalah makan ini, sehingga pemberian vitamin dan susu yang berlebihan bukanlah langkah tepat menghadapi masalah tersebut, bahkan dapat mencetuskan masalah makan anak[21].

Keberhasilan pembinaan makan anak ditentukan oleh faktor sosial-budaya serta pengetahuan orang tua. Ada tiga tipe orang tua dalam pemberian makan anak yaitu controlling, laissez -faire, dan responsive. Perilaku controlling, orang tua selalu menentukan dan mengontrol porsi, waktu, dan menu makan anak sehingga terkesan otoriter. Laissez-faire bertolak belakang dengan controlling, tidak ada paksaan terhadap anak, meskipun gizi anak tergolong gizi kurang. Orang tua responsif akan selalu berada dekat anaknya, merespon setiap tangisan anaknya dengan memberinya makan. Perilaku ibu ini akan berpengaruh dalam pemilihan dan penyiapan makanan dan keamanannya, yang akan memengaruhi fungsi endokrin dan gungsi fisiologis lainnya. Orang tua yang otoriter akan menghambat regulasi proses makan anak secara mandiri sehingga anak cenderung kelebihan berat badan[20].

Hasil penelitian Rosita (2014) tentang Faktor yang berhubungan dengan sulit makan pada anak pra sekolah di TK Pertiwi Jepara mendapatkan bahwa sebagian besar sulit makan disebabkan oleh faktor penyajian makanan tidak menarik $61,8 \%$, faktor psikologis $52,9 \%$, dan faktor organ tubuh yang tidak sehat $17,6 \%$. Penyajian makan berkaitan dengan ekonomi keluarga, kurangnya kreatifitas ibu tentang cara penyajian makanan serta pemilihan variasi makanan yang disukai anak.faktor psikologis berkaitan dengan anggapan bahwa segala cara harus dilakukan agar anak bersedia makan termasuk dengan cara kasar seperti mengancam atau menghukum anak jika menolak untuk makan[22].

\section{KESIMPULAN}

Terdapat hubungan yang bermakna antara factor pengetahuan ibu tentang gizi balita, factor pola makan balita dengan status gizi balita di wilayah kerja Puskesmas Sidomulyo kota Pekanbaru. Semakin baik pengetahuan ibu dan pola makan balita yang diterapkan maka akan semakin baik pula status gizi balita.

Disarankan agar tenaga kesehatan di Puskesmas Sidomulyo kota Pekanbaru melakukan pengkajian dengan baik tentang kondisi gizi balita agar dapat menyusun langkah yang tepat sesuai dengan penyebabnya untuk memperbaiki status gizi balita, seperti meningkatkan pengetahuan dan kepedulian ibu tentang gizi balita melalui penyuluhan disertai media kontekstual dan simulasi penyajian nutrisi yang meningkatkan minat makan 
balita. Meningkatkan pengetahuan tentang pola pemberian makan yang sesuai dengan usia balita serta upaya-upaya efektif untuk tetap memenuhi kebutuhan nutrisi balita yang mengalami masalah/kesulitan makan.

\section{DAFTAR PUSTAKA}

[1] WHO, "Children: Reducing Mortality," 2018.

[2] Kementerian Pemberdayaan Perempuan dan Perlindungan (KPPA), "Profil Anak Indonesia 2018," Jakarta, 2018.

[3] Kemenkes RI, "Profil Kesehatan Indonesia Tahun 2017," Jakarta, 2018.

[4] Barness and John, Ilmu Kesehatan Anak Nelson Vol. 1. Jakarta: EGC, 2000.

[5] Bonnin, "Feeding problems of infant and toddlers," 2006.

[6] Nassar, "Masalah makan pada anak," 2006.

[7] M. Wright, N. Parkinson, and D. Shipton, "How to toddler eating problems relate to their eating behavior, food, preferences and growth?".

[8] S. Mawarni, "Hubungan pengetahuan ibu tentang MP-ASI dengan Perilaku pemberian MP-ASI dan Status gizi pada Baduta usia 624 bulan di Kelurahan Kestalan Kecamatan Banjarsari Kota Surakarta," 2013.

[9] D. . Supariasa and B. Bakri, Penilaian Status Gizi. EGC, 2002.

[10] Milda Riski Nirmala Sari and Leersia Yusi Ratnawati, "Hubungan Pengetahuan Ibu tentang Pola Pemberian Makan dengan Status Gizi Balita di Wilayah Kerja Puskesmas Gapura Kabupaten Sumenep," Amerta Nutr., pp. 182188, 2018.

[11] M. Sari and L. Ratnawati, "Hubungan Pengetahuan Ibu tentang Pola Pemberian Makan denga Status Gizi Balita di Wilayah Kerja Puskesmas Gapura Kaupaten
Sumenep," Amerta Nutr., pp. 182188, 2018.

[12] Ihsan, "Faktor-faktor yang berhubungan dengan status gizi Balita di Desa Teluk Rumbia Kecamatan Singkil Kabupaten Aceh Singkil.," J. Gizi Indones., vol. 22, no. 3, pp. 44-54, 2012.

[13] J. Manary and W. Noel, Aspek Kesehatan masyarakat pada gizi kurang: gizi kesehatan masyarakat. Jakarta: EGC, 2010.

[14] A. M and W. B, Pengantar Gizi Masyarakat. Kencana, 2012.

[15] G. Sari, G. Lubis, and Edison, "Hubungan Pola Makan dengan Status Gizi Anak Usia 3-5 tahun di Wilayah Kerja Puskesmas Nanggalo Padang 2014," J. Kesehat. Andalas, vol. Vol 5 No 2, pp. 391-394, 2016.

[16] A. Tella and Cessy, "Hubungan Pola makan dengan status gizi pada balita di wilayah kerja Puskesmas Paniki Kecamatan Mapanget, Manado: Program Studi Ilmu Keperawatan Fakultas Kedokteran Universitas Sam Ratulangi,” ejournal keperawatan (e-Kp), vol. 1, no. 1, pp. 1-6, 2013.

[17] C. Yulia, "Pola Asuh Makan dan Kesehatan Anak Balita pada Keluarga Wanita Pemetik Teh di PTPN VIII Pandeglang," Repos. IPB, 2008.

[18] K. Dewi, Ilmu gizi untuk praktisi kesehatan. Yogyakarta: Graham Ilmu, 2012.

[19] Katz, Manikam, and Schuberth, "Pediatric Feeding Problems," Schills EM, pp. 875-80, 2006.

[20] Hamzah, "Masalah makan pada anak," 2006, pp. 59-65.

[21] Sudjatmoko, "Masalah makan pada anak," vol. Vol 10 No., pp. 36-41, 2011.

[22] D. Rosita, U. Lathifah, and A. Sholikah, "Faktor-faktor yang berhubungan dengan sulit makan pada anak pra sekolah di TK Pertiwi Desa Bugel Kecamatan Kedung 
Kabupaten Jepara," J. Kesehat. dan Budaya HIKMAH, vol. Vol 5 No., pp. 33-37, 2014. 